\title{
Development of High Performance Automatic Voltage Stabilizer for Telecommunication Applications
}

\author{
J.P. Karunadasa and S.S.K. Thotagamuwage
}

\begin{abstract}
The telecommunication industry in Sri Lanka is showing fast growth and expands services to their customers, especially during past decades, by increasing number of service providers with much competitive Tariffs. The main challenge of the service provider is to sustain with the competitive Tariff reductions and advancement of their services to customer doorstep demanding by the industry. Not like in other industry, the telecom customer is having the freedom to select any service provider by own decision without facing any monopoly or other influence by the industry. This automatically creates the industry to reduce their OPEX \& CAPEX continually. The CAPEX is always increasing and the reduction possibility exists only with OPEX in the telecom industry.
\end{abstract}

Electricity contributes to the major portion of OPEX of remote telecom site operations. The electricity by means of Diesel Generator (DG) operation or Commercial supply (CEB/ LECO) is always a difficult facility in remotely operated telecommunication base stations. This is due to the nature of the location of the selected site and the quality of the nearest/ rural commercial supply. Due to this, the site needs to run with the DG in most of the period of the day or face with service outages due to interruptions of the electricity with huge OPEX and unexpected losses in income.

The main objective of this research project is to develop a system for automatic voltage regulation at remote telecommunication sites with customized features. The outcomes of this research will be a remarkable development in the telecom industry. We also supposed to share this knowledge with all the interesting parties to extend the benefits not only to the telecom service providers, but also to the customers by means of lowest tariffs.

\section{Index Ternits}

Voltage, Stabilizer, Power, Telecom, Cost

\subsection{Introduction}

\subsection{Objectives}

Low Voltage \& power quality interruptions are common problems in most of the Telecom Radio Base Stations (RBSs) in Sri Lanka; mainly due to the specific locations of the selected sites to suite the transmission requirements [3]. The best site in terms of transmission can be located at top of mountain or far away to a populated area where the clear line-of-site, coverage \& transmission capacity is optimum. In considerable cases, nearest power line is more than $1.5 \sim 3 \mathrm{Kms}$ away \& the line drawn up to the site will not maintain the standard voltage.

Sample characteristic graphs of Normal CEB power input (Voltage, Current \& Frequency) with all loads are as follows.

The sites where the voltage is low/ higher than the acceptable range $(230 \mathrm{~V}+/-10 \%)$, the standby Generator will be connected to the system and operate continually, until the voltage is corrected. The sites where the standby power is not available, the systems are critically operated with the available unclean power, however to maintain unbreakable service and systems are face with frequent failures. The operation cost in terms of Diesel, portal charges, frequent maintenance \& technical attention will be much higher.

The main objective of this paper is to present the practical approach on developing a system for automatic voltage regulation at remote sites and incorporate advanced customized features \& facilities for the exact use of telecom operators, to minimize their power related operational problems.

Eng. (Dr.) J.P. Karnuadasa, BSc. Eng (Moratuwa), MSc (Manch), PhD (Manch), CEng, MIE(Sri Lanka), Senior Lecturer in Electrical Engincering,Grade "1", Presently Head of the Department of Electrical

Engineering

Eng. S.S.K. Thotagamuwage, B.Sc. Eng.(Hons) at University of Moratutia, M.Sc. in Electrical Installations at University of Morafuzwa, AMIE (Sri Lanka), Electrical Engincer by Profession, Manager, Planning \& Standardization at Lanka Bell Limited. 

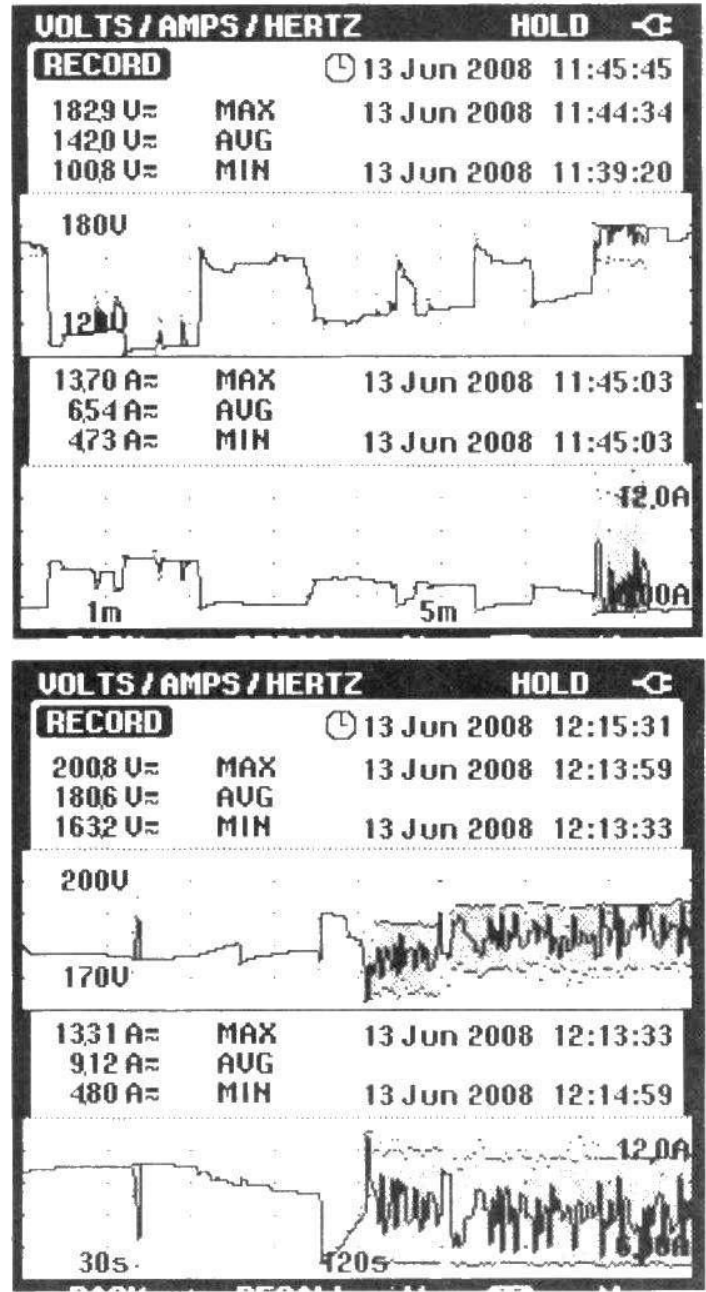

Fig 1.1: Characteristic graphs (Voltage, Current \& Frequency) of (EB power in BIS site

Sample characteristic graphs of Normal CEB power input (Sags \& Swells and THD) to the cabin with all loads are as follows.

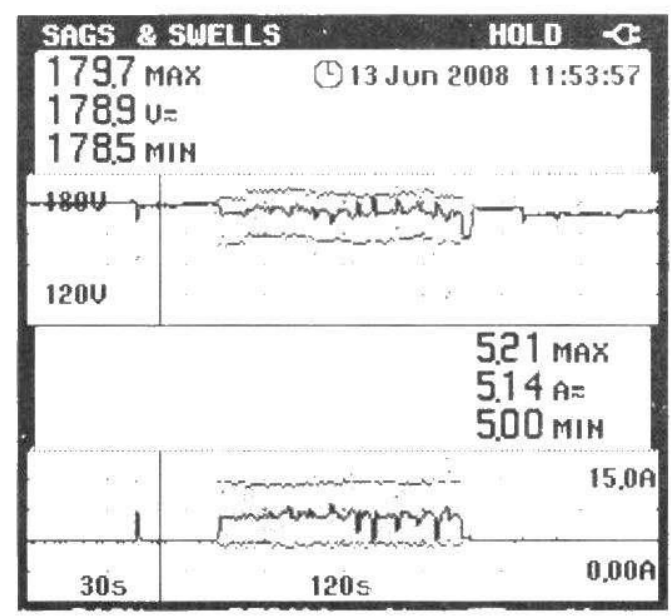

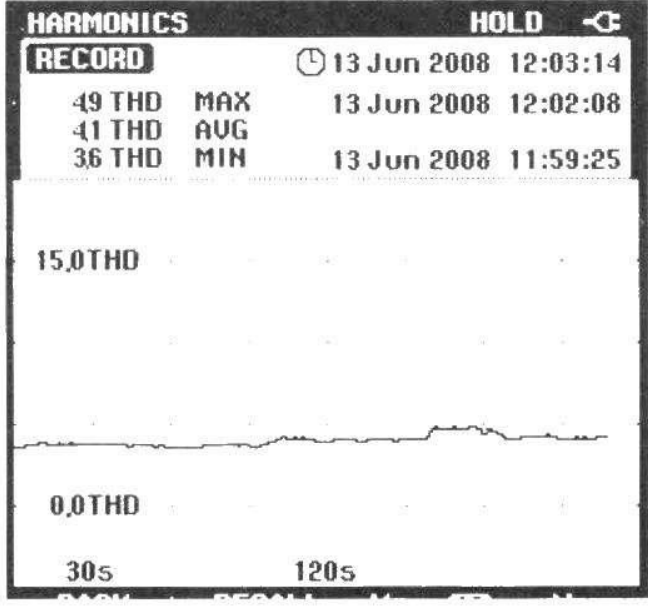

Fig 1.2: Characteristic graphs (Sags \& Swells and THD) of CEB power in BTS site

\subsection{Proposed Features}

The unit is expected to operate under extreme climatic, environmental \& power abnormality conditions to regulate \& maintain reliable \& accurate sinusoidal voltage profile to the sensitive electronic \& telecommunication equipment. In addition, the development meets the protection requirements specified by these equipment, modular construction for easy customization and easy maintenance at regular intervals. Increased sistem efficiency, output power qualitv, fast voltage correction, long life of operation, noise free regulation, automatic monitoring, controlling \& operation, relatively small construction with lightweight package at lowest possible cost, are some of the expected outcomes of this development

\subsection{Power Quality}

Especially for the telecommunication svstem. to function properly, it is necessary to make sure that the power feeding them is of a sufficient quality to ensure that the performance is not impaired or system life expectancy is not reduced.

Without the proper power, an electrical device or load may malfunction, fail prematurely or not operate at all. There are many ways in which electric power can be of poor quality and many more causes of such poor quality.

The most common solution for those power quality problems in industry is to have online UPS (Uninterruptible Power Supply) and will often be viewed as the obvious choice [1] However, these are usually expensive to buy and have high ongoing maintenance and support costs. Automatic Voltage Stabilizer / Regulator or AC Power Conditioner will be a 
far more cost efficient solution both in terms of initial outlay, ongoing maintenance, support costs and the required local skill sets required to install, maintain and support the solution [2].

Voltage fluctuations defined as repetitive or random variations in the magnitude of the supply voltage. The magnitudes of these variations do not usually exceed $10 \%$ of the nominal supply voltage. The characteristics of voltage fluctuations depend on, load type, size, and the power system capacity.

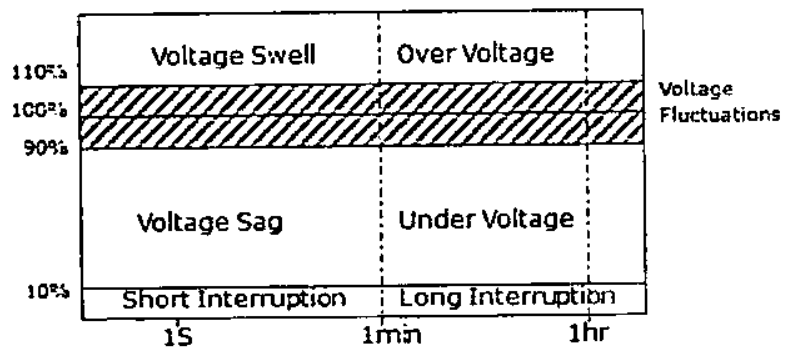

Fig 1.3: Categories of voltage fluctuations

Various solutions are available to achieve best power quality, which provide varying degrees of protection/ features at different prices in the market.

\subsection{Theoretical development}

\subsection{Mathematical modeling}

Consider the simple model representing a fluctuating load drawing real power $\mathrm{P}$, and reactive power $Q$ connected to a power system with impedance of resistance $R$, and reactance $X$, as illustrated bellow. The voltage $V_{R}$ seen by the customer can usually be regulated by operating the system voltage $V_{S}$ at a slightly higher value to ensure $V_{R}$ remains at the required value. During steady state operation, this can be achieved through the use of automatic tap changers on transformers, line drop compensators and voltage stabilizers [24].

The resultant voltage due to the current drawn by the load is illustrated in the phase diagram, where $V_{S}$ is the supply voltage and $V_{R}$ is the resultant voltage seen by the load at the point of common connection (PCC).
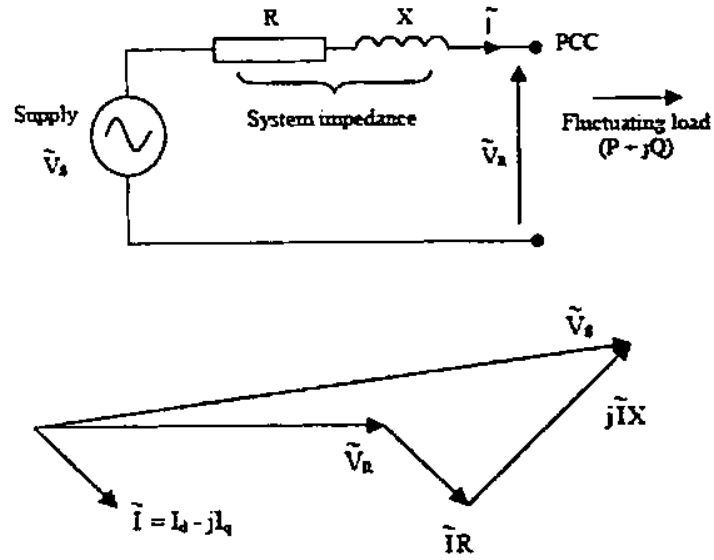

Fig 2.1: Phase diagram of Voltage \& Current

The complex power drawn by the fluctuating load and the voltage phases can be described by equations (1) and (2) respectively.

$V_{R} I^{\star}=P+j Q$

$V_{S}=V_{R}+I(R+j X)$

Expanding equation (2) for the voltage phases provides the following

$V_{S}=V_{R}+\left(I_{d}-j I_{q}\right)(R+j X)$

$V_{S}=\left(V_{R}+R I_{d}+X I_{q}\right)+j\left(X I_{d}-R I_{q}\right)$

Ignoring the phase differences between $V_{R}$ and $V_{S}$ in equation (4) and equating only the real parts

$V_{S}=V_{R}+R I_{d}+X I_{q}$

Assuming $\mathrm{V}_{\mathrm{S}}$ is a very strong supply system, i.e. $V_{s}$ remains constant regardless of the current drawn by the fluctuating load, for any changes in $I_{d}$ and $I_{q}$ the changes in $V_{R}$ will be as follows

$0=\Delta \mathrm{V}_{\mathrm{R}}+\mathrm{R} \Delta \mathrm{I}_{\mathrm{d}}+\mathrm{X} \Delta \mathrm{I}_{\mathrm{q}}$

$\Delta \mathrm{V}_{\mathrm{R}}=-\left(\mathrm{R} \Delta \mathrm{I}_{\mathrm{d}}+\mathrm{X} \Delta \mathrm{I}_{\mathrm{q}}\right)$

Equation (7) can be re-written in per unit, i.e. in terms of the changes in real and imaginary power drawn by the fluctuating load

$\Delta \mathrm{V}_{\mathrm{R}}=-(\mathrm{R} \Delta \mathrm{P}+\mathrm{X} \Delta \mathrm{Q})$

If $R$ is negligible, then the reactance $X=1$ / Fault level, leading to equation (9)

$\Delta V_{R}=-\Delta Q /$ Fault level 
Thus, it can be seen that the voltage at the point of common connection is essentially a function of the reactive power variation of the load and supply system characteristics.

Note that for low voltage systems where $R$ is considerably larger the real power may also contribute significantly to voltage variations.

The above $\Delta V_{R}$ voltage correction range can be corrected by the Voltage stabilizer.

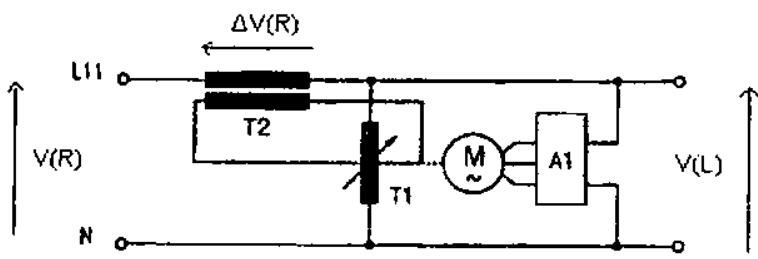

Fig 2.2: Voltage stabilizer block diagram

The T2 Booster transformer will adjust the $V_{R}$ by changing the tapping points of the $\mathrm{T} 1$ variable transformer in order to correct and keep stable the load voltage $V_{L}$.

The resultant voltage at the load can be represented as per equation (10) bellow.

$V_{L}=V_{R}+\Delta V_{R}$

Design \& sizing of the stabilizer system including the autotransformer, servomotor and the control system to suite the Telecom site requirement can be summarized as follows. The following example calculation can be given.

Input voltage $=140-240 \mathrm{~V}\left(\Delta \mathrm{V}_{\mathrm{R}}=100 \mathrm{~V}\right)$

Output voltage $=230 \mathrm{~V}$ accuracy $\quad 1.5 \%$ (recommended accuracy level for the sensitive equipments in operation)

Power capacity $=7.5 \mathrm{KVA}$ (considering the average power required for a base station equipments)

Adjusted speed $=10 \mathrm{~V} / \mathrm{sec}$ (fast response for not-to-operate the standby generator by under/ over voltage protections settings)

Select Autotransformer of capacity $7.5 \mathrm{KVA}, 1 \mathrm{ph}$ with input voltage range $140-240 \mathrm{~V}$, turns 200 (selected to improve the voltage adjustment accuracy) and the servomotor selected as $50 \mathrm{~W}$ (motor capacity selected from manufacturer to suite the above configurations [6,25]), 12V DC with speed suitable for $10 \mathrm{~V} / \mathrm{sec}$ movements by controlled shaft displacement of the rolling brushed on the winding turns.
The cross section of the windings can be assumed by the followings manner.

$\Delta \mathrm{V}_{\mathrm{R}}(100 \mathrm{~V})=\mathrm{R}$ (winding) $\times \mathrm{I}$ (winding)

$R=\rho L / A \quad$ where $\rho-C u$ resistivity, $L-$ length, $A$ - cross section of winging.

$R=\Delta V_{R}(100 \mathrm{~V}) / \mathrm{I}$ (winding) $\quad$ where $\mathrm{I}=7.5 \mathrm{x}$ $100 \mathrm{VA} / 230 \mathrm{~V}=32.6 \mathrm{~A}$

The A \& $R$ of the windings of the autotransformer can be sized as above. In addition, the other design \& sizing can also be done in the same simple way to order the stabilizer.

\subsection{Development Steps}

The development is having 4 steps as described bellow.

1. Identify the existing arrangements \& abnormalities in various stations and limitations associated with, by several on site surveys.

2. Analyze the problem, solutions \& related issues by categorizing the sites to few "RBS models" which represent the overall, to make easy implementation.

3. Technical approach to Identify design parameters \& methodologies for each RBS models.

4. Improve \& enhance the performance of the voltage stabilization system.

\subsection{Design Parameters Considered}

The design parameters in terms of Electrical, Environmental, Protection, Monitoring \& Equipment construction requirements for each of the RBS Models, should be identified in detail. The objective of this that, the customized solutions to compatible \& operate under the design conditions, with minimum operational issues. The following parameters were finalized after several site surveys.

\section{Electrical Data:}

Rated input voltage, Input voltage correction, Rated frequency, Mains input capability, Rated output voltage, Accuracy of adjustment, Output waveform, Response time, Efficiency, Rated current/ power, Input Power 
factor, Loading balance, Loading time, Rated short-time current \& Overload Capacity.

\section{Environment Conditions:}

Ambient temperature, Relative humidity, Installation altitude, Climatic surroundings, Bedewing possible \& Pollution possible.

\section{Protection Requirements:}

Thermal-magnetic overload, Main on/ off switch, Transient voltage Surge, Phase loss sensing, Automatic output delay on system, built in IP enclosure, Installation location, Leakage current, Earth fault, Enclosure ventilation, Bypass-circuit options, Isolation transformer, EMI interference filter, RFI interference filter, Output fuse \& Stall protection for Servo Motors.

\section{Equipment Construction:}

Available volume, Enclosure construction, Enclosure mounting, Weight of the AVS unit \& Reliability (MTBF).

\section{Monitoring Facilities:}

Phase indication, Ampere meter, Voltmeter \& Remote alarm.

\subsection{Theoretical Approach}

The theoretical approach for implementing each of the features and guaranteed outcome of the proposed features are as follows. Most of the outcomes are directly applicable for telecom operations [20], [21], [22].

1. Expanded input voltage window by Higher rated windings/ power circuits designed on extreme case scenario.

2. Fast respond for voltage correction to get proper RMS output by Small stepped servo transformer and Increasing speed/ performance of the synchronous servo motor.

3. Short adjustment time by Servomotor with high starting torque to get proper RMS output.

4. Stops immediately after switching off \& start back in very short time by Selfstarting synchronous motor with permanent field.

5. Higher reliability in Operation with best available phase by Phase selector with single-phase servo that possible to feed from all 3 phases.

6. Non distorted sine wave output by Static line conditioner \& Isolation Transformer in series to the system.

7. Prevent from RF \& EM interference (common mode and differential mode noise emissions) to receive quality supply from the distorted input power by RFI/EMI/EMC/EFT filter blocks.

8. Precise degree of rotation motion to get Minimum of output voltage error by System amplifier with closed loop control circuit.

9. Protection from transient voltage surge or spikes by MOVs across the input.

10. Protection from Lighting and Surge by Class-B \& C surge diverters.

11. Over Voltage and Under Voltage protection by Electronic relay which monitors the output and activated to disconnect input. Also actuate audible or visual alarms.

12. Protection from overloading or short circuit conditions for Quick isolation of incoming supply by High quality $\mathrm{MCB}$ incorporated to the system.

13. Manual or Emergency by-pass in case of emergency or maintenance by Push button wired with by pass path from incoming to the load.

14. Protections from harmonic currents \& improve power factor to Reduce harmonic currents, spikes, fault currents \& save on the electricity costs by Line reactors.

15. Output reactors/ chokes to Protect motor from over voltage failures associated with long cable runs, Reduces motor temperature \& audible noise by Output reactors/ chokes.

16. Higher reliability \& trouble free performance of servo motor for Long life of operation without trouble or worn out of brushers by Selflubricating carbon roller assemblies on a fiberglass carrier board.

17. Minimize losses in terms of copper losses \& iron losses in operation by Wound with heavy section of multi strips electrolytic copper and special lamination. 
18. Overall $M \& E$ equipment management for Gen, AC, Fan automatically select only when required by Main Controller panel incorporate with equipment in automatic operation.

19. Basic status monitoring of the unit for on-site reference on the unit operation and conditions of power by Analog voltmeters, ammeters, phase indicator lamps, etc on the panel front.

20. Remote Monitoring of the unit status to attend immediately for rectification by the dry connectors of the BTS used to extend the alarm to the NOC with relays operated when output tripped off due to exceeded voltages.

21. Auto restart on main return and Startup delay protection to Prevent damages to inductive load equipments under transient condition by Delay timer on startup after transient conditions.

22. Module/ Detachable construction for Easy customization to suite variety of installation, transportation \& replacement conditions to facilitate for on site dissemble \& reconnecting. PCBs compactly designed and fixed in such a manner that it can be easily removed and reconnected.

23. Proper maintenance attention for extended lifetime of the unit by on-site instructions on the routing maintenance and scheduled visits for the same. On site minimum spare stocks for easy replacement.

24. Enclosure construction for outstation use for higher reliability in Operation with long life. Prevents moisture and contaminants in harsh environments by IP 54/55 protection against solid/ liquid ingress. Louvers for ventilation and the openings are covered with neoprene gasket for dust proof.

25. Electronic components for long hour trouble free operation by Electronic components used of high quality and properly soldered for long hours of continuous trouble free operation. Internal fans for forced ventilation.

26. Lowest in Weight \& facilities for movement/ least transportation for Easy transportation \& movements by using lest weight components for the construction. Include lockable rollers for movement \& handles for carrying with connecting supporters.

27. Low noise operation with minimum friction by Gear arrangements that are properly aligned to give smooth, free low noise operation with minimum friction. Used self lubricants on moving parts with auto refilling back once empty.

28. Energy-efficient motor operation for Lowest in the cost of operation on electricity. Lengthening the core and using lower-electrical-loss steel, thinner stator laminations, and more copper in the windings reduce electrical losses. Improved bearings and a smaller, aerodynamic cooling fan further increase efficiency.

\subsection{Results and Analysis}

\subsection{Overview}

The outcomes can be categorized as direct financial benefits, operational overhead reductions \& technical benefits. The results can be obtained by referring various reporting sources and the recorded improvements can be identified.

\subsection{Direct Financial Benefits}

- Recover the revenue from network up time

- Customer satisfaction due to unbreakable service

- Reduction of expenses for failure recovery due to power problems

- Minimum part replacements with reduction of equipment failures

- Other financial benefits related to network revenue

\subsection{Operational Overhead Reductions}

- Minimum use of Diesel Generator for the operation

- Minimum attention \& visits for day to day failure recoveries

- Low routine maintenance visits with reduction of maintenance cost 


\subsection{Technical Benefits}

- Improve the efficiency of power to equipments, hence low electricity cost

- Extending the equipment operational lifetime with quality power \& reduce interruptions

- Maintain the room temperature in the recommended range for healthy operation.

- Reduce the losses in the equipments in operation with quality power

- Reduced environmental \& power surges in to the room and improved protection

\subsection{Reduction of the Network Outage Time}

The "CDMA Outage Report" generated by the Network Operation Center (NOC) will gives the outage time of each month at all the Base stations with the reasons on such failures.

The customer service outage is comparatively higher in remote sites due to various reasons such as link fading due to rain/ wind, Radio equipment malfunctioning due to environment condition (temp \& RH) variations, limited on site fuel for the extended generator operation, CEB power line breakdowns, etc.

Those are unavoidable to some extend. However, by preventive methods such as proper network designing, cover-up with backup links, proper power conditioning, etc, those can be minimized to an economical level.

The downtime reduction with the "power" conditioning by the stabilizer system introduced could be seen in Fig 3.1.

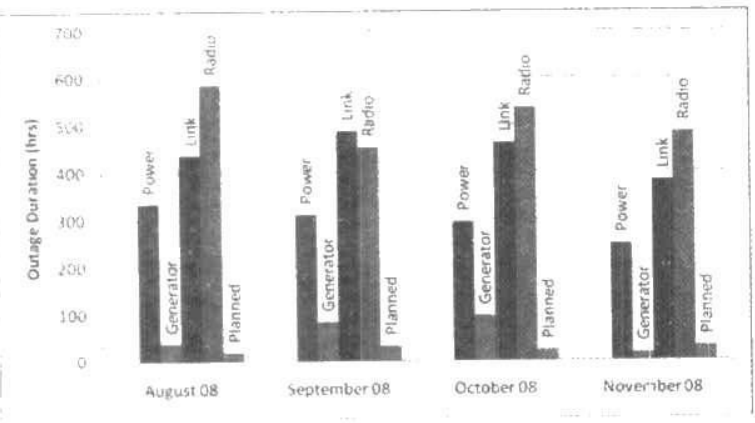

Fig 3.1: Network Outage characteristics
3.6 Reduction of the Customer Complains

The 24 hrs $\times 365$ days operating "Customer care unit" with over 100 of agents are handling the Customer related problems.

The "Customer Complain Report" will provide complains with the following categories and that will represent the number of events faced by the customers due to the given technical failures.

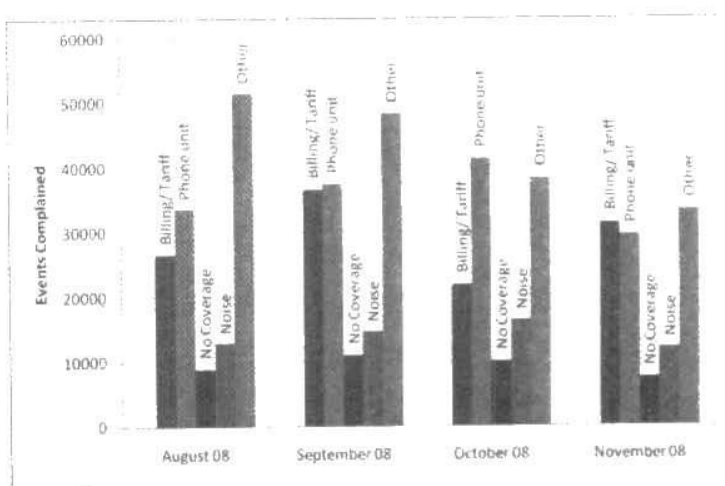

Fig 3.2: Customer Complain patterns

3.7 Reduction of the Operational Overhead

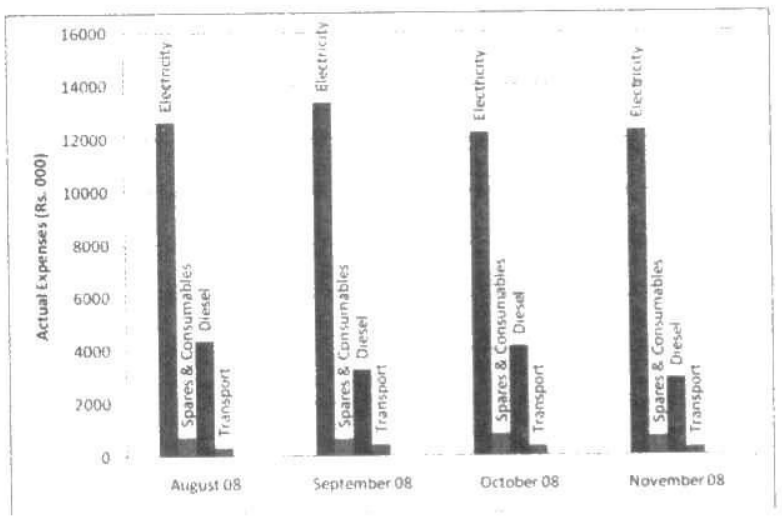

Fig 3.3: Operational Overhead variations

The operational overhead such as Generator operation time, spare replacement, electricity, etc could be seen considerable reduction due to the introduction of the stabilizer system. Pls refer the author's "MSc Thesis" [25] for more details on financial savings.

The above graph shown a significant reduction of OPEX especially on Electricity, Spare, Diesel and Transport, which are related with power quality of the base, station sites. 


\subsection{Conclusion}

The main objective of this project was to suggest the most economical way of running the remotely located low voltage sites by reducing the customer service interruptions while minimizing the OPEX on day to day operations. With the recorded data after one month test running period, remarkable results could be obtained and also proved that the projects is financially viable.

This development will help the company to face the challenging marketplace to sustain with the competitive Tariff reductions and demanding advancement of services to customers with minimum investment. Not like in other industry, the telecom customer is having the freedom to select any other service provider by their own decision without facing any monopoly or other influences. This automatically creates the industry to reduce their OPEX \& CAPEX continually to sustain with the market share. The CAPEX is always increasing and the reduction possibility exists only with OPEX. This project could save the major portion of the OPEX by keeping other facilities in better condition and this was a remarkable achievement.

The test observations proved that the system develop for the automatic voltage regulation at remote telecom sites can operate under extreme climate, environmental \& power abnormality conditions to regulate \& maintain reliable \& accurate sinusoidal voltage profile to the sensitive telecommunication equipments, without any single failure to the systems. In addition, the development of the unit is capable of meeting the protection requirements from various environmental/ power abnormalities and kept the sites free from any outside effects.

We believe that, the outcomes of this research will be a remarkable development in the telecom industry. We also supposed to share this knowledge with all the interesting parties to extend the benefits not only to the telecom service providers, but also to the customers by means of further reduction in tariffs.

\section{Acknowledgement}

I would like to thanks my supervisor, Dr J.P. Karunadasa, Head of Electrical Engineering department, for his right direction, great insights, guidance and sense of humor. My sincere thanks go to the former Head of Electrical Engineering department Professor
H.Y.R. Perera, course coordinator, Dr. Lanka Udawatta and all the academic staff who helped in various ways to clarify the things related to my academic works in time with excellent cooperation and guidance. Sincere gratitude is also extended to the people who serve in the Department of Electrical Engineering.

I also thanks to Mr. Krishan Gamage \& Mr. Kusal Saranath, who gave special guidance on clarifying technical matters and, Anura Liyanage for his time on helping me to conduct the preliminary technical surveys and gathering technical literatures in many of the sites in various places in Sri Lanka.

Lastly, I should thanks many individuals \& friends who have not been mentioned here personally in making this educational process a success. May be I could not have made it without your supports.

\section{Reference}

[1] Robin Koffler, Jason Yates, "The Power Protection Guide", Technical Guide of Riello UPS, vol. 1, pp 15-33, 2007.

[2] Web Site:

http://www.ashleyedison.com, Ashley-Edison International Limited.

[3] J.W.D.Somasundara, N.N.K.P.Withanage, "Problems and Prospects of Telecommunications Services in the Ratnapura District", Research Paper published in TRCSL website, pp 235-238, 2006.

[4] H.S.C Perera, "Services Quality and Telecommunications Services in the Southern Province in Sri Lanka", Research Paper published in TRCSL website, pp 106-139, 2004.

[5] Flanagan, William, "Handbook of Transformer Design and Applications", McGraw-Hill, pp 22-65, 1993.

[6] V.N. Mittle, A. Mittal, “Design of Electrical Machines", Standard Publishers Distributors, Delhi, 4th edition, pp 1-81, 2006.

[7] Callister, Jr., William D, "Materials Science and Engineering - an Introduction", 5th edition, John Wiley and Sons, pp 14-98, 2000.

[8] A. Draper, "Electrical Machines", Longaman Inc, 7th edition, pp 35-189, 1967. 
[9] Website:

www.emersonnetworkpower.com, Emerson Network Power Co., Ltd Homepage.

[10] Dale R. Patrick, Stephen W. Fardo, "Electrical Motor Control Systems", The Goodheart- Willcox Company, Inc Publisher, pp 100-100, 1999.

[11] John N. Chiasson, "Modeling and High Performance Control of Electric Machines", Wiley-IEEE Press, New York, 2005.

[12] Donald R. Wulfinghoff, "Energy Efficiency Manual", Energy Institute Press, 2004.

[13] Donald R. Wulfinghoff, "The Four Steps of Effective Energy Management", Wulfinghoff Energy Services, Inc, pp 12-346, 2004.

[14] John C. Andreas, "Energy Efficient Electric Motors - Selection \& Applications", 2nd edition, Marcel Dekker Inc, pp 65-258, 1992.

[15] Nandike Pathirage, "Solving the Under Voltage problem in Sri Lanka National grid", Thesis for MSc at University of Moratuwa, 2001.

[16] P.C. Devasurendra, "Investigation of Voltage Profile in Low voltage Distribution Network", Thesis for MSc at University of Moratuwa, 2006.

[17] Web Site: http://www.success.com.my, Success Electronic \& Transformer manufacturer Limited Homepage.

[18] Donald G. Fink and H. Wayne Beaty, "Standard Handbook for Electrical Engineers", Eleventh Edition, McGrawHill, New York, 1978.

[19] Bandula S. Tilakasena, K.A. Noel Priyantha, "End-user characteristics of the electricity demand in Sri Lanka", Research paper published in CEB website, 2001.

[20] M.T.K. De Silva, "Design of Power Electronic Inverter for Active power reduction in an unbalance 3 phase system", Thesis for MSc at University of Moratuwa, pp 33-33, 2004.

[21] G.Weerasekara, "Voltage Sag mitigation using Dynamic voltage restore with multi-feedback control", Thesis for MSc at University of Moratuwa, pp 33-33, 2005.

[22] H.C.S. Hettigoda, “Hardware Implementation of a Power system stabilizer", Thesis for MSc at University of Moratuwa, 2002.

[23] Website: http://www.wapa.gov, Western Area Power Administration, an agency of U.S. Department of energy website.

[24] Professor V.J. Gosbell, "Voltage fluctuations in the electric supply system", Technical Note for Integral Energy Power Quality Centre, University of Wollongong, 2003.

[25] S.S.K Thotagamuwage, "Development of High Performance Automatic Voltage Stabilizer for

Telecommunication Applications", Thesis for MSc at University of Moratuwa, Chapter 7, 2008. 